\title{
A sub-representação do futebol praticado por mulheres no jornalismo esportivo de Portugal: um estudo sobre a Algarve women's football cup
}

\author{
Silvana Vilodre Goellner \\ Paula Silva** \\ Paula Botelho-Gomes ${ }^{* * *}$
}

\begin{abstract}
Resumo: Fundamentada nos estudos culturais e de gênero, esta pesquisa analisa a cobertura que o jornal esportivo português A Bola empreendeu sobre a $19^{\underline{a}}$ edição da Algarve Women's Football Cup. Como fontes foram consideradas todas as edições de A Bola on-line publicadas durante a competição, assim como reportagens veiculadas nos jornais Recorde, O Jogo e O Norte Desportivo. A análise do material empírico evidencia que a sub-representação do futebol praticado por mulheres acontece pelo ínfimo número de reportagens publicadas, pela valorização de uma representação tradicional de feminilidade e pela pouca visibilidade conferida à modalidade e suas atletas.
\end{abstract}

Palavras-chave: Mulheres. Futebol. Meios de comunicação. Esportes. Identidade de gênero.

\section{INTRODUÇÃO}

No mês de outubro de 1923, o cenário esportivo português foi agitado pela presença de uma delegação de atletas francesas que fizeram várias exibições atléticas em Lisboa, Coimbra e Porto. A imprensa não silenciou esse acontecimento inclusive porque essas sportwomen protagonizaram a aparição do futebol praticado por mulheres ${ }^{1} \mathrm{em}$ Portugal. O ineditismo de tal presença foi matéria recorrente em vários jornais da época, assinalando reações polêmicas sobre a inserção das mulheres em um esporte tido como violento e, portanto, não adequado à natureza de seu sexo (CRUZ, 2003).

\footnotetext{
"Professora da Escola de Educação Física da Universidade Federal do Rio Grande do Sul. Porto Alegre, RS, Brasil. E-mail: vilodre@gmail.com

"Faculdade de Desporto da Universidade do Porto. Porto. Portugal. E-mail: psilva@fade.up.pt "*Faculdade de Desporto da Universidade Lusófona. Porto. Portugal. E-mail: paulabotelhogomes@gmail.com

${ }^{1} \mathrm{~A}$ utilização do termo "futebol praticado por mulheres" se dá em contraposição à expressão corriqueiramente utilizada "futebol feminino". Sob a ótica dos estudos de gênero, sugere uma alteração conceitual e política em função da compreensão de que masculino e feminino são atributos culturais e não necessariamente relacionados ao sexo biológico.
} 
Passados quase 90 anos dessa primeira aparição, o cenário esportivo é outro: o futebol integra o calendário esportivo nacional com competições específicas, existem várias atletas federadas, e a seleção portuguesa participa de eventos importantes da modalidade, tais como os Jogos Olímpicos e os Mundiais de Futebol. Ainda assim, tal aparição continua sendo motivo de polêmicas, a exemplo da matéria publicada na edição de fevereiro de 2012 na revista Maxim Portugal, na qual se lê:

Bem sei que o futebol é comumente aceite como um desporto para homens mas se até eles já se depilam não consigo entender porque razão só jogam à bola mulheres com bigode, e convenhamos, com os joelhos metidos para dentro ao ponto de se achar piada de mau gosto a verificação de que... há futebol feminino em Portugal. Mais valia chamar de "toucinho feminino" à modalidade porque as gajas boas que vão aos estádios [...] não jogam à bola. (SANTOS, 2012).

Para além do caráter preconceituoso que permeia essa citação, a participação das mulheres no futebol português tem sido negligenciada de outro modo, qual seja, a pouca visibilidade que a modalidade tem no âmbito do jornalismo esportivo, cujos registros focalizam, quase que por unanimidade, o futebol jogado pelos homens.

Fundamentada no aporte teórico dos estudos culturais e dos estudos de gênero, esta pesquisa analisa a cobertura que $A$ Bola on-line empreendeu sobre a $19^{\mathrm{a}}$ edição da Algarve Women's Football Cup, denominada também Mundialito de Futebol Feminino, realizada entre os dias 28 de fevereiro e 7 de março de 2012.

A opção pelo recorte analítico de gênero ancora-se na percepção de que o esporte, como qualquer outra prática cultural, é generificado e generificador. Ou seja, seu acontecer está perpassado pela produção e reprodução de relações de poder, conferindo, em grande medida, maior visibilidade aos homens nesse campo específico (HARGREAVES, 1994; SILVA; BOTELHO-GOMES; 
GOELLNER, 2011). Além disso, como categoria analítica (SCOTT, 1995), o gênero evidencia que as representações de feminilidade e masculinidade não são neutras nem universais. Ao contrário: constroem-se cotidianamente, considerando as representações culturais a elas associadas. São também produzidas por meio de processos de aprendizagem que se fazem presentes nos discursos médicos, familiares, religiosos, pedagógicos, jurídicos e naqueles que circulam nos diferentes artefatos midiáticos.

O campo dos estudos culturais permite analisar que a mídia, tanto quanto o esporte, ao promover diferenciações nos modos pelos quais noticia, exibe e confere visibilidade a atletas, competições, clubes e acontecimentos esportivos, exerce o poder de definir quem está incluído e quem está excluído daquilo que é narrado.

Considerando essas premissas, o presente artigo tem como objetivo ressaltar que a sub-representação do futebol praticado por mulheres em um importante periódico esportivo de Portugal mostrase como outra barreira enfrentada pelas jogadoras, pois, além de não serem reconhecidas, sequer são consideradas como protagonistas da história do esporte naquele país. Por essa razão, ainda é possível identificar narrativas que as tomem como impróprias em um espaço esportivo cuja história oficial tem demarcado como de soberania dos homens.

\section{AAlgarve Women's Football Cup}

Aprovada pela Federação Internacional de Futebol (FIFA), a primeira edição da Algarve Women's Football Cup, denominada também Mundialito de Futebol Feminino, aconteceu em março de 1994 e, desde então, ocorre anualmente na região do Algarve, chegando à sua 19a edição em 2012.

Ao longo de sua existência, aconteceram algumas alterações, conferindo ao campeonato maior importância no cenário esportivo internacional. Dentre elas, destaca-se o acréscimo de países 
participantes por edição ${ }^{2}$, um maior envolvimento da FIFA através da escalação de árbitras profissionais desde 2005 e a visibilidade do campeonato junto a federações esportivas internacionais.

Desde o princípio da competição já passaram pelos campos do Algarve as seleções de Alemanha, Austrália, Áustria, Canadá, Chile, China, Dinamarca, Escócia, Estados Unidos, Ilhas Faroé, Inglaterra, Finlândia, França, Grécia, Holanda, Hungria, Irlanda, Irlanda do Norte, Islândia, Itália, Japão, México, Noruega, País de Gales, Polônia, Portugal, Romênia, Rússia e Suécia. Ou seja, esse não é um campeonato desprovido de importância para o circuito esportivo internacional. Para além de reunir um número expressivo de seleções nacionais, sua realização é considerada como um espaço não apenas para a divulgação do futebol praticado por mulheres mas, sobretudo, para a própria qualificação das equipes, na medida em que, desde sua primeira edição, o evento conta com a presença de seleções que venceram os Jogos Olímpicos ${ }^{3}$ e a Copa do Mundo ${ }^{4}$.

Considerando esse contexto, a pesquisa apresenta um recorte qualitativo (BOGDAN; BIKLEN, 1994), tendo como recorte temporal o período de 27 de fevereiro a 8 de março de 2012, ou seja, um dia anterior e um dia posterior à realização do Mundialito de Futebol Feminino.

\footnotetext{
${ }^{2}$ Em 1994 participaram quatro seleções e em 1995 esse número foi ampliado para oito. Desde 2002, o torneio é disputado por 12 equipes.

${ }^{3} \mathrm{~A}$ inserção do futebol praticado pelas mulheres nos Jogos Olímpicos aconteceu em 1996 nos jogos de Atlanta, sendo campeã a equipe dos EUA, que venceu também em 2004 (Atenas) e 2008 (Pequim). Nos Jogos Olímpicos de Sidney (2000), a Noruega ficou com o título. Com exceção dos EUA (apenas em 1996) e da Alemanha (em 2000 e 2004), todas as equipes campeãs e as colocadas em segundo e terceiro lugares participaram do Mundialito no ano correspondente ao título. Exceção se faz ao Brasil (vice-campeão em 2004 e 2008).

${ }^{4}$ A primeira Copa do Mundo de Futebol Feminino aconteceu em 1991, tendo como vencedora a seleção dos Estados Unidos. Desde então se sagraram campeãs as equipes da Noruega (1995), dos EUA (1999), da Alemanha (2003 e 2007) e do Japão (2011). Com exceção da Alemanha (apenas em 2003), todas as equipes campeãs participaram do Mundialito no ano correspondente ao título. Com relação ao segundo e terceiro lugares, apenas a Alemanha não participou em 1995. Exceção novamente ao Brasil (terceiro lugar em 1999 e segundo em 2007), que nunca participou desse evento.
} 
Para a sua elaboração, tomamos como fonte primária todas as edições on-line publicadas nesse período por $A$ Bola $^{5}$, considerado o jornal esportivo português mais acessado no país (COELHO, 2004) pois, além de manter a edição diária impressa e digital, evidenciou seu protagonismo no cenário nacional com o lançamento, em março de 2012, da Bola TV, caracterizando-se como o único no país a manter esse suporte informacional.

A opção por analisar as matérias na versão on-line se deu em função da possibilidade que o webjornalismo tem de noticiar os acontecimentos em tempo real, promovendo assim a atualização instantânea "na tela do computador na forma de textos, gráficos, imagens, animações, áudio e vídeo; recursos multimídia que estão ampliando as possibilidades dos media" (MARTINS, 2008).

No período de abrangência da pesquisa, foram publicadas 10 edições digitais de $A$ Bola, cujas principais reportagens foram disponibilizadas na seção Notícias, com atualização permanente, somando em média 100 matérias veiculadas diariamente. Desse montante, consoante aos objetivos desta pesquisa, foram selecionadas e analisadas todas as reportagens relacionadas ao futebol praticado por mulheres, totalizando cinco, o que corresponde a um percentual de $0,52 \%$ das 949 reportagens publicadas pelo jornal ${ }^{6}$. Como fontes complementares, foram catalogadas e analisadas todas as reportagens específicas sobre o Mundialito publicadas na versão digital dos jornais esportivos portugueses Recorde (17 reportagens), $O$ Jogo On-Line (quatro reportagens) e O Norte Desportivo (uma reportagem) no mesmo período de cobertura.

\footnotetext{
${ }^{5} \mathrm{O}$ jornal A Bola foi fundado em 1945 como um semanário de notícias esportivas. No ano de 1995, mudou para o formato tablóide, passando a ser publicado diariamente. A edição on-line foi lançada no dia 29 de janeiro de 2000 e pode ser acessada através do endereço eletrônico <http:/ /www.abola.pt>.

${ }^{6} \mathrm{~A}$ Bola on-line publicou 949 reportagens. Destas, 860 tematizaram o futebol e 89 outras modalidades esportivas tais como tênis, automobilismo, ciclismo, natação e atletismo. Das 860 reportagens específicas sobre o futebol, apenas cinco se referiram ao futebol praticado por mulheres, totalizando um percentual de $0,58 \%$.
} 
O diálogo entre as diferentes fontes empíricas foi desenvolvido tendo como ferramenta metodológica a análise de conteúdo proposta por Bardin (1988), cuja efetivação se deu a partir de três fases distintas: a pré-análise, na qual foi realizada a organização do material empírico, nesse caso, todas as notícias publicadas pelos jornais escolhidos sobre temas relacionados a mulheres e futebol. Posteriormente foi realizada a exploração desse material, caracterizada pela codificação a partir das unidades de registro. Desse procedimento resultou a etapa de tratamento dos dados, que foram categorizados e interpretados considerando-se os objetivos da pesquisa.

As imagens foram analisadas a partir da perspectiva proposta por Gillian Rose (2007), que envolve três instâncias: os espaços de produção da imagem, o espaço da imagem em si e os espaços em que a imagem é visualizada pelos diversos públicos.

Considerando os pressupostos teórico-metodológicos que fundamentam a pesquisa, do material empírico analisado, destacaramse duas unidades de significado: a sub-representação do futebol praticado por mulheres no jornalismo esportivo português e a reafirmação de uma representação ${ }^{7}$ tradicional de feminilidade, as quais serão desenvolvidas a seguir.

\section{A BOLA ON-LINE E A SUB-REPRESENTAÇÃO DO FUTEBOL PRATICADO POR MULHERES}

Não há duvidas de que o esporte tornou-se um fenômeno cultural de grande abrangência e visibilidade no cenário mundial. Parte da sua popularização pode ser atribuída à intensa relação do esporte com a mídia, a qual, através de seus diferentes artefatos, tem possibilitado que eventos de pequeno, médio e grande porte sejam acessados em diferentes sociedades, produzindo assim novas informações e, também, novos consumidores. Tal acessibilidade tem sido facilitada por vários motivos, tais como a expansão quantitativa

\footnotetext{
${ }^{7}$ Representação é aqui entendida como uma construção que envolve as práticas de significação e os sistemas simbólicos através dos quais os significados são elaborados. Envolve relações de poder, definindo quem está incluído e quem está excluído.
} 
da comunicação midiatizada (tiragens e audiências), a diversidade dos suportes midiáticos (jornal, rádio, televisão, revistas, internet, redes sociais, entre outros), a rapidez na produção da informação (o chamado "tempo real") e o crescimento vertiginoso dos setores voltados para produção, circulação, difusão e consumo de bens simbólicos, entre eles a própria informação (RUBIM, 2003).

O futebol integra esse processo e se constitui como o principal tema de grande parte do jornalismo esportivo nas sociedades ocidentais modernas, fundamentalmente na sua expressão de alto rendimento, inscrita, sobretudo, no futebol profissional praticado pelos homens. Em Portugal esse cenário não é diferente, e os três jornais esportivos mais lidos pela sua população ( A Bola, Record e O Jogo) apontam para essa direção, tanto nas suas versões impressas quanto no suporte digital (MARTINS, 2008; COELHO; TIESLER, 2006).

A centralidade no futebol praticado por homens reafirma-se ao analisarmos a escassez de informações sobre o Mundialito de Futebol Feminino na agenda da imprensa esportiva portuguesa. Essa sub-representação se fez notória na pauta de A Bola on-line dado o ínfimo percentual destinado a noticiar esse evento, somando apenas $0,58 \%$ das notícias que publicou sobre futebol no período analisado.

Tal sub-representação já havia sido apontada em estudo realizado por Cláudia Pinheiro (1996), tendo como justificativa para tal desigualdade questões de ordem econômica, visto que a maioria do público que lê jornais esportivos prefere artigos sobre o esporte praticado pelos homens. Segundo a autora, "ao serem elaboradas as notícias, os jornalistas, editores bem como todos os outros responsáveis procuram satisfazer os interesses dos leitores, dado que isso traduzir-se-á numa maior venda de jornais, o que significa maiores lucros financeiros" (p. 3).

Passados mais de dez anos da realização desse estudo, alguns dados parecem não ter sofrido alteração. Segundo o relatório da 
pesquisa Sociedade em Rede em Portugal 2011, desenvolvida pelo Observatório da Comunicação, de 121 entrevistados, 63\% dos que leem jornais em papel e on-line são do sexo masculino. Quando avaliados os perfis de leitores de jornais, os resultados demonstram que há mais leitores do sexo masculino, sendo que a

[...] grande diferença (aproximadamente $70 \%$ ) se situa ao nível do consumo dos jornais desportivos, ainda que os valores apontem para um predomínio de leitores do sexo masculino, qualquer que seja o tipo de publicação em análise - semanários, temáticos, generalistas etc. (OBSERVATÓRIO DA COMUNICAÇÃO, 2011, p. 43).

Esses dados demonstram que a prevalência do esporte vivenciado pelos homens ainda figura como central na agenda esportiva de Portugal, mesmo que tenha aumentado o número de mulheres esportistas. Conforme dados apresentados pelo Pordata Base de Dados Portugal Contemporâneo, de 2003 para 2010 o percentual de mulheres atletas federadas aumentou de $18,6 \%$ para $24,7 \%{ }^{8}$.

Considerando que a mídia tem um papel fundamental na divulgação do esporte (KENNEDY; HILLS, 2009; ROWE, 2004) e, consequentemente, no incentivo para a sua prática (LINES, 2007), o pouco espaço, visibilidade e reconhecimento ao esporte de mulheres tem promovido não apenas a marginalização das atletas nesse campo específico (BIRREL; COLE, 1994), mas também a anulação simbólica de suas realizações, sobretudo em modalidades culturalmente representadas como de domínio dos homens, a exemplo do futebol (HARGREAVES, 1994).

A inexpressiva cobertura que A Bola on-line fez sobre o Mundialito Feminino de Futebol pode ser analisada sob essa ótica.

\footnotetext{
${ }^{8}$ Os valores apresentados só incluem federações desportivas dotadas do estatuto de utilidade pública esportiva (enquanto entidades que promovem, regulam e dirigem, no plano nacional, a prática das diversas modalidades desportivas) que se candidataram no ano a financiamento público. Disponível em: <http://www.pordata.pt/Subtema/Portugal/Desporto-192>. Acesso em: 4 abr. 2012.
} 
Além dos aspectos quantitativos, considerando-se o número mínimo de reportagens que publicou, os aspectos qualitativos - observação do que foi noticiado e como foi noticiado - apontam para a mesma direção.

Durante os nove dias de competição, foram publicadas cinco reportagens ${ }^{9}$ de caráter eminentemente informativo, indicando $\mathrm{o}$ resultado das partidas, os gols marcados, o nome da atleta que os fizeram e o tempo de jogo em que aconteceram. Além de serem curtas (três ou quatro frases), nenhuma delas confere voz às atletas. A única reportagem na qual aparece uma entrevista é a que noticia a colocação de Portugal na competição, em que o A Bola on-line concede a António Violante, treinador da seleção portuguesa, o direito de se expressar.

Comparativamente com a cobertura feita pelo jornal esportivo Record, nas 17 reportagens que publica, além da fala de Violante leem-se também entrevistas com Carla Couto (atleta da seleção portuguesa), Mônica Jorge (ex-técnica da seleção e atual diretora para o futebol feminino da Federação Portuguesa de Futebol), Susana Cova (treinadora adjunta da seleção portuguesa) e Pia Sundhage (técnica da seleção dos Estados Unidos). Foi esse mesmo jornal (o único em Portugal) que publicou a entrevista do presidente da FIFA em comemoração ao Dia Internacional da Mulher (8 de março). Intitulada "Blatter: Futebol feminino tem mais dimensão social do que o masculino."10, a matéria deu visibilidade à participação das mulheres nesse esporte, ressaltando sua importância tanto para o desenvolvimento da modalidade quanto para a emancipação das mulheres.

No jornal $O$ Norte Desportivo, na única e minúscula reportagem que publicou sobre o Mundialito, as mulheres é que

\footnotetext{
9"Portugal estreia-se a perder diante o País de Gales" (29 de fevereiro), "Portugal goleia Hungria" (2 de março), "Portugal derrota Repúbica da Irlanda" (5 de março), "Portugal perde com a China e fica em $10^{\circ}$ no Mundialito" (7 de março) e "Alemanha derrota Japão (4-3) e vence Mundialito" (7 de março).

${ }^{10}$ Disponível em <http://www.record.xl.pt/Futebol/Nacional/futebol_feminino/interior.aspx? content_id=745046>. Acesso em: 5 abr. 2012.
} 
tiveram o direito de fala. Intitulada "Mundialito termina hoje no Algarve", a matéria reproduz fragmentos das falas das capitãs das equipes do Japão, Aya Miyama, e da Alemanha, Nadine Angerer, em entrevista coletiva antes da disputa final ${ }^{11}$.

Para além de A Bola on-line não publicar nenhuma fala das mulheres que se envolveram nesse campeonato (atletas, árbitras, treinadoras ou dirigentes), as imagens que veicula denotam a subrepresentação das mulheres. Das cinco reportagens, três delas são ilustradas com a mesma fotografia, na qual se vê apenas António Violante à beira do campo, em uma posição que sugere o repasse de orientações para as jogadoras. A imagem que figura na reportagem de encerramento da competição exibe a seleção alemã, em posição oficial, segurando um painel contendo o nome da competição e os patrocinadores. Aúnica reportagem que exibe uma atleta em situação de jogo é a que faz referência à vitória de Portugal frente à Irlanda, na qual Ana Borges (que marcou dois gols na partida) é fotografada de frente, da cintura para cima, em um cenário difuso.

Ainda que a imagem tenha sido produzida durante o jogo, não se vê a jogadora em ação, executando algum gesto técnico da modalidade. Diferentemente, as imagens publicadas em Record, em sua imensa maioria, registram as atletas realizando gestos esportivos próprios à modalidade (chutes, dribles, passes), ou ainda no momento de comemoração de um gol.

$\mathrm{Na}$ perspectiva teórica que fundamenta esta pesquisa, a imagem é tomada como uma prática social discursiva e linguisticamente construída. É um texto que, além de conter signos, símbolos e significados, cria sentidos, expressa relações de poder, enuncia posições de sujeito (ROSE, 2007). A imagem, portanto, não é neutra nem inocente, e a não exibição das atletas em situação de jogo parece indicar que esse lugar não lhes pertence ou, como vários estudos têm apontado, que as realizações e conquistas das atletas mulheres não são tão importantes quanto às dos atletas homens

${ }^{11}$ Disponível em: http://www.oprimeirodejaneiro.pt/edicoes/2652.pdf>. Acesso em: 5 abr. 2012. 
(CLAVIO; EAGLEMAN, 2011; BILLINGS; ANGELINI, 2007; FULLERTON, 2006; SOUSA, 2002). Essa representação produz efeitos na prática cotidiana do futebol como, por exemplo, a menor adesão de mulheres jovens a esse esporte, se comparado a outras modalidades, inclusive, o futsal. Baseado em dados do Instituto do Desporto de Portugal, a Associação Portuguesa Mulher e Desporto ${ }^{12}$ aponta que a taxa de feminização do futebol no escalão de formação (até Júnior) é de $0,7 \%$, ou seja, o número de moças praticantes é bastante reduzido em relação aos rapazes. Esse dado é corroborado em pesquisa desenvolvida sobre a percepção de jovens jogadores e jogadoras de futebol e seus pais, cujos resultados indicam que, devido à visibilidade midiática do futebol e porque "se vê na prática desta modalidade um trampolim para um futuro melhor, é frequente o pai investir particularmente na formação de seu filho na modalidade, não existindo, de uma forma geral, o mesmo interesse pela filha, quando é esta que pratica o futebol" (MATEUS, 2009).

Levando em consideração que a presença da mídia impacta de forma direta o cotidiano dos sujeitos (MEZZAROBA; MESSA; PIRES, 2011), é necessário destacar o quanto a produção da agenda esportiva é generificada e, consequentemente, atravessada por relações de poder. Ao abordar a relação entre a ação da mídia e o conjunto de conhecimentos sobre a realidade social, Wolf (2001) destaca três características: a acumulação (poder da mídia em criar/ manter a relevância de um tema), a consonância (mensagens mais semelhantes que dessemelhantes) e a onipresença (difusão quantitativa da mídia).

Ao não dar maior destaque para o Mundialito na sua agenda de notícias, o jornal A Bola on-line posicionou o futebol praticado por mulheres como menos interessante, pouco atrativo e sem importância para o desenvolvimento do esporte nacional. Com isso, deixou de contribuir para quebrar o ciclo vicioso no qual a baixa

\footnotetext{
${ }^{12}$ Criada em 1996, a Associação Portuguesa Mulher e Desporto tem desenvolvido várias ações, buscando potencializar o esporte feminino em Portugal. Dentre elas destaca-se o projeto $O$ Jogo das Raparigas, cujo objetivo principal é contribuir para o aumento da participação de moças e mulheres no futebol/futsal. Mais informações disponíveis em: <http:// www.mulheresdesporto.org.pt/web/index.php>.
} 
adesão das mulheres ao futebol se dá em função de sua pouca valorização e, na contramão dessa história, a pouca adesão acontece pela pouca visibilidade e reconhecimento. Afinal, estar na agenda dos jornais esportivos significa também existir, pois:

[...] em consequência da acção dos jornais, da televisão e dos outros meios de formação, o público sabe ou ignora, presta atenção ou descura, realça ou negligencia elementos específicos dos cenários públicos. As pessoas têm tendência para incluir ou excluir dos seus próprios conhecimentos aquilo que os mass media incluem ou excluem do seu próprio conteúdo. (WOLF, 2001, p. 55).

A negligência de A Bola on-line com relação ao futebol praticado por mulheres, aqui analisado a partir da ínfima cobertura que fez ao Mundialito, não significa que elas estejam ausentes de suas páginas digitais. Ao contrário: em todas as edições publicadas, a presença das mulheres se fez constante em uma seção específica, denominada A Bola de Estrelas, no entanto essas não eram as mulheres que jogaram bola.

\section{A Bola de Estrelas E A REAFIRMAÇÃo dE UMA DADA FEMINILIDADE}

Ao longo da realização do Mundialito, a seção A Bola de Estrelas foi atualizada cinco vezes, e todas as reportagens publicadas continham um número significativo de imagens. Seus títulos são representativos do que $A$ Bola on-line quer noticiar: "Tamara Ecclestone, a filha do patrão da Fórmula 1 é uma bomba" (20 fotos); "Nereida Gallardo: Depois de Cristiano Ronaldo... Quinaz..." (8 fotos); "Como elas ficaram famosas à conta do futebol (parte 1)..." (26 fotos); "Da Playboy à campeã olímpica, dize-se que é (ou foi) amante de Putin..." (47 fotos).

Além dessas matérias, a única que exibe jogadoras de futebol foi publicada no dia 5 de março, com o título "Beleza norte-americana à solta no Algarve (com fotos)". Assinada por Redação, a matéria é 
ilustrada por uma imagem na qual se vê Hope Solo de corpo interiro, nua, de perfil, regando com uma mangueira o gramado verde de um jardim. Diz a legenda: "A foto que mais impacto causou no ensaio fotográfico de Hope Solo na ESPN Body". Ao final da matéria, são exibidas mais 18 imagens, 11 delas são da goleira americana (em quatro aparece nua) e oito exibem a atacante Alex Morgan, com destaque para o ensaio fotográfico de bodypaint realizado para a revista Sports Illustrated. O texto da reportagem refere-se ao jogo entre as seleções americana e japonesa que, segundo a Redação é uma "oportunidade para apreciar a qualidade futebolística de algumas das melhores jogadoras do Mundo e... não só"13.

Ao analisarmos quantitativamente as reportagens que $A$ Bola on-line veiculou no período aqui analisado, é possível perceber o mesmo número de publicações. No entanto, além de as matérias de A Bola das Estrelas serem mais extensas, o número de fotografias que exibe não deixa dúvidas de que são alguns corpos de mulheres que o jornal faz ver, enquanto outros são colocados na sombra. Mais especificamente: os corpos que circulam nas suas páginas, além de não serem de esportistas, quando são enfatizam uma dada representação de feminilidade na qual os atributos estéticos suprimem os atributos técnicos das jogadoras de futebol, sub-valorizando assim suas realizações atléticas e esportivas. Nas palavras de Catherine Louveau (2001, p. 42):

[...] do desportista em ação, é descrito o que faz. O mesmo não acontece com as desportistas, de quem os comentadores não sabem dizer o que elas fazem sem passarem pelo que elas parecem. É essa uma das especificidades do desporto no feminino: não pode ser comentado sem que seja apreciada a estética daquela que o pratica.

Em relação especificamente às modalidades esportivas socialmente representadas como mais apropriadas aos homens, tais como o futebol, vários estudos apontam que, não raras vezes, o modo

\footnotetext{
${ }^{13}$ Disponível em: <http://www.abola.pt/galerias/ver.aspx?id=319418>. Acesso em: 4 abr. 2012.
} 
como as notícias são produzidas apontam ainda para a suspeição acerca da sexualidade das atletas, sobretudo sobre sua heterossexualidade (WRIGHT; CLARKE, 1999; COX; THOMPSON, 2000; HARRIS, 2005; FERRETI et al., 2011).

Esse modo de relatar acontecimentos que giram em torno do universo cultural do esporte acaba por reforçar desigualdades e hierarquias de gênero nas quais os corpos masculinos no esporte valem mais do que os femininos. Com isso, reitera-se a representação de que o esporte, fundamentalmente o futebol, é praticado por homens e noticiado para homens. A Bola on-line, ao não visibilizar o Mundialito de Futebol Feminino nem as performances esportivas das atletas das 12 seleções mundiais que participaram do campeonato, reforça essa representação. Constrói, ainda, o perfil dos seus leitores, quando investe prioritariamente em um modo de representar as mulheres a partir daquilo que os homens se interessam em olhar, exibindo imagens erotizadas do corpo feminino, um objeto de consumo e de desejo.

\section{CONSIDERAÇõES FINAIS}

A sub-representação do futebol praticado por mulheres no jornal A Bola on-line pode ser observada tanto a partir de dados quantitativos quanto qualitativos, especialmente quando observamos o que registrou e o modo como registrou nas suas páginas um importante evento da modalidade.

O ostracismo ao qual a modalidade é submetida indica o quanto o agendamento midiático é generificado. Seja porque pouca visibilidade confere ao esporte praticado por mulheres, seja porque quando o faz não rompe com a reprodução de representações de feminilidade nas quais atributos como sensualidade, beleza, erotismo e graciosidade são valorizados. Historicamente, essa repetição tem gerado efeitos perversos no campo esportivo, dificultando inclusive a ampliação da feminização da modalidade. 
Se pensarmos que a mídia produz valores, significações, saberes e identidades que de algum modo educam as pessoas, ensinandolhes modos de ser e estar no mundo, é fácil imaginar o quanto uma alteração na forma de exibir o futebol vivenciado pelas mulheres poderia potencializar o esporte, conferindo-lhes outros sentidos e significados. Mais do que isso, faria justiça a quem, desde há muito tempo, também o protagoniza e constrói cotidianamente a sua história. 
Under-representation of women's football in the Portuguese sports newspaper: a study of Algarve women's football cup

Abstract: Grounded on Cultural Studies and Gender Studies, this research analyzes the approach given by A Bola sports newspaper to the 19th edition of Algarve Women's Football Cup. As primary sources, we have considered all the on-line editions of $A$ Bola published along the competition and also specific reports about published in the following newspapers: Recorde, O Jogo and O Norte Desportivo. The analysis of the empiric material has evidenced that the underrepresentation of women's football occurs because of the small number of published reports, of the valorization of a traditional femininity representation and due to little visibility given to this modality and its athletes.

Keywords: Women. Soccer. Communications media. Sports; Gender Identity.

La sub representación del fútbol practicado por mujeres en el periodismo deportivo de Portugal: un estudio sobre la Algarve women's football cup

Resumen: Fundamentada en los Estudios Culturales y de Género esta investigación analiza la cobertura que el periódico deportivo portugués A Bola emprendió sobre la 19a edición de la Algarve Women's Football Cup. Como fuentes fueron consideradas todas las ediciones de A Bola on-line publicadas durante la competición así como reportajes vehiculadas en los periódicos Recorde, O Jogo y O Norte Desportivo. El análisis del material empírico evidencia que la sub representación del fútbol practicado por mujeres sucede por el ínfimo número de reportajes publicadas, por la valorización de una representación tradicional de feminidad y por la poca visibilidad conferida a la modalidad y sus atletas.

Palabras clave: Fútbol. Mujeres. Medios de comunicación. Deportes. Identidad de género. 


\section{REFERÊNCIAS}

BARDIN, Laurence. Análise de conteúdo. Lisboa: Edições 70, 1988.

BILLINGS, Andrew; ANGELINI, James. Packaging the games for viewer consumption: gender, ethnicity, and nationality in NBC's coverage of the 2004 Summer Olympics. Communication Quarterly, New York, v. 55, n. 1, p. 95-111, Feb. 2007.

BIRREL, Susan; COLE, Cheryl L. Women, sport and culture. Champaign: Human Kinetics, 1994.

BOGDAN, Robert; BIKLEN, Sari. Investigação qualitativa em educação: uma introdução aos métodos. Porto: Porto Editora, 1994.

CLAVIO, Galen; EAGLEMAN, Andrea N. Gender and sexually suggestive images in sports blogs. Journal of Sport Management, Champaign, v. 25, n. 4, p. 295304, Jun. 2011.

COELHO, João Nuno. "Vestir a camisola" - jornalismo desportivo e a selecção nacional de futebol. Media e Jornalismo, Coimbra, v. 4, p. 27-39, mai./jun. 2004.

COELHO, João Nuno; TIESLER, Nina. O paradoxo do jogo português: a omnipresença do futebol e a ausência de espectadores dos estádios. Análise Social, Lisboa, v. 41, n. 179, p. 519-551, abr./jun. 2006.

COX, Barbara; THOMPSON, Shona. Multiple bodies: sportswomen, soccer and sexuality. International Review for the Sociology of Sport, London, v. 35, n. 1, p. 5-20, Mar. 2000.

CRUZ, Isabel. Sportwoman: a contrução dos corpos desportivos femininos na imprensa desportiva portuguesa da década de 20. Dissertação (Mestrado) - Curso de Estudo sobre Mulheres, Departamento do Sociologia, Universidade Aberta de Lisboa, Lisboa, 2003.

FERRETI, Marco Antônio et al. O futebol feminino nos Jogos Olímpicos de Pequim. Motriz, Rio Claro, v. 17, n. 1, p. 117-127, jan./mar. 2011.

FULLERTON, Romaine S. Not playing fair: coverage of women and minorities in the sports pages. Simile: Studies in Media \& Information Literacy Education, Toronto, v. 6 , n. 2 , p. $1-13$, set. 2006 .

GOELLNER, Silvana V. Feminismos, mulheres e esportes: questões epistemológicas sobre o fazer historiográfico. Movimento, Porto Alegre, v. 13, n. 2, p. 171-196, maio/ago. 2007.

HARGREAVES, Jeniffer. Sporting females: critical issues in the History and Sociology of women's sports. London: Routledge, 1994.

HARRIS, John. The image problem in women's football. Journal of Sport \& Social Issues, London, v. 29, n. 2, p. 184-197, Sep. 2005. 
KENNEDY, Eileen; HILLS, Laura. Sport, Media and Society. Oxford: Berg, 2009.

LINES, Gill. The impact of media sport events on the active participation of young people and some implications for PE pedagogy. Sport, Education and Society, New York, v. 12, n. 3, p. 317-334, Jul. 2007.

LOUVEAU, Catherine. Desporto, mulheres, media: o corpo desejável das desportistas. Ex-Aequo, Vila Franca de Xira, v. 4, p. 57-74, set. 2001.

MARTINS, Hugo Miguel L. Imprensa desportiva: uma análise comparativa entre Portugal, Espanha e Itália. Dissertação (Mestrado) - Curso de Comunicação, Cultura e Tecnologia da Informação, Departamento do Sociologia, Instituto Superior de Ciências do Trabalho e da Empresa, Lisboa, 2008.

MATEUS, Ana Luisa Tomé. Percepção da competência física do futebol feminino e masculino: um estudo com jovens jogadores e seus pais. Monografia (Licenciatura em Desporte e Educação Física) - Faculdade do Desporto, Universidade do Porto, Porto, 2009.

MEZZAROBA, Cristiano; MESSA, Fábio; PIRES, Giovani de Lorenzi. Quadro teóricoconceitual de referência: megaeventos e o agendamento midiático-esportivo. In: PIRES, Giovani de Lorenzi. O Brasil na Copa, a Copa no Brasil. Florianópolis: Tribo da Ilha, 2011. p. 21-45.

OBSERVATÓRIO DA COMUNICAÇÃO. A imprensa na sociedade em rede 2011. Lisboa, 2011. Disponível em: <http://www.obercom.pt/client/?newsld= 548\&fileName=fr_sr_julho_2011_imprensa.pdf >. Acesso em: 7 maio 2012.

PINHEIRO, Maria Cláudia Brandão. Os media e o desporto: análise dos géneros masculino e feminino nos jornais desportivos. In: CONGRESSO PORTUGUÊS DE SOCIOLOGIA, 3., 1996, Lisboa. Anais... Lisboa: Celta Editora, 1996. Disponível em: <http://www.aps.pt/cms/docs_prv/docs/DPR492edd6946cdd_1.pdf>. Acesso em: 9 set. 2012.

ROSE, Gillian. Visual methodologies: an introduction to the interpretation of visual materials. London: Publications, 2007.

ROWE, David. Sport, Culture and the Media: the Unholy Trinity. Maidenhead: Open University Press, 2004.

RUBIM, Antônio A. C. Definindo a mídia na contemporaneidade. Idade Mídia, São Paulo, v. 2, n. 3, p. 7-21, jun. 2003.

SCOTT, Joan. Gênero: uma categoria útil de análise histórica. Educação \& Realidade, Porto Alegre, v. 20, n. 2, p. 71-99, jul./dez. 1995.

SILVA, Paula; BOTELHO-GOMES, Paula; GOELLNER, Silvana V. Masculinities and sport: the emphasis on hegemonic masculinity in Portuguese physical education classes. International Journal of Qualitative Studies in Education, New York, v. 25, n. 3, p. 269-291, Jan 2011. 
SANTOS, Rui. Sexy League. Os estereótipos do mundo da bola: se elas - as gajas boas - jogassem futebol. Maxim Portugal, Lisboa, p. 78-79, 20 fev. 2012.

SOUSA, Jorge Pedro. Estereotipização e discurso fotojornalistico nos diários portugueses de referência: os casos do Diário de Notícias e Público. Disponível em: <http://www.bocc.ubi.pt/pag/sousa-jorge-pedro-estereotipizacaodiscurso-fotojornalistico.pdf >. Acesso em: 21 set 2012.

WOLF, Mauro. Teorias da comunicação. Lisboa: Editorial Presença, 2001.

WRIGHT, Jan; CLARKE, Gill. Sport, the media and the construction of compulsory heterosexuality: a case study of Women's Rugby Union. International Review for the Sociology of Sport, London, v. 34, n. 3, p. 227-243, Sep. 1999.

Auxílio financeiro: $\mathrm{CNPq}$

Endereço para correspondencia:

Silvana Goellner

Centro de Memória do Esporte

ESEF/UFRGS

Rua Felizardo, 750

Jardim Botânico

Recebido em: 03.01.2013

Aprovado em: 25.04.2013

Movimento, Porto Alegre, v. 19, n. 03, p. 171-189, jul/set de 2013. 